\title{
Die Brandenburgische Hebammenlehranstalt und Frauenklinik in Neukölln
}

Am, 3. Oktober ist die neuerbaute Hebam,m.enlehranstalt der Provinzial-verwaltung von Brandenburg eingeweiht worden.

Im Verfolgd.es langgehegten Planes, die dxei bisherigen Hebamm.en-lehranstalten Lübben, Frankfurt a. O. und in d.er Charité einheitlich zu-sammenzufassen, hat d.er Brandenbiu gische Provinziallandtag zur Feier de $5 / 825$ jährigen Regierung sjubilälım d.es Kaisers beschlossen, einen eihheitlichen Bau in Neukölln zu errichten. Diese volkreiche Berliner VorOrtstadt stiftete hierfür ein Grundstück von 31/2 Hektar. Trotz der Ungxmst der Zeit ist der Neubau von 1914 bis heute fertiggestellt worden. Dem Baumeister Goecke stand von Anfang an Prof. Hammerschlag zur Seite.

Es Wurde beschlossen, die Hebammenlehranstalt mit einer Frauenklinik zu verbinden. In dem zẁeistöckigen Entbindungshaus liegen eämt-liche mit Wöchnerinnen, KLranken und Säuglingen besetzten Räum,en nach Süden; die Operations- und Entbindungs£äle sind in den nach Norden sich erstreckenden 3 Flügelanbauten untergebracht. Im $7 / 8$ dgesehoß befindet sich an und in den Seitenflügeln die allgem.eine geburtshülflicheAbteüung..

466

Personalien.

Außßrdem vorläufig ein Säuglingsheim iür 16 Mutter und 24 Säuglinge, bis das von Neukölln geplant $\subset$ C eigene Säuglingsheim, iür Welches auf der gegen-überliegenden Seite der breiten Straße der Platz schon ausgelegt ist, fertig-gestellt wird. Im 1. Obergeschoß ist die Privatabteilung für Wöchnerinnen I. und II. Klasse, mit besonderem Entbindungssaal und ein $\beta$ Abteilung für Wöchnerinnen III. Klasse gelegen. Die hellen luftigen Entbindungssäle mit den Ilntersuchungs- und Operationsräum, en liegen nach Norden. Das 2. Obergeschoß enthält eine Abteilung für septische Wöchnerinnen und die gynä-kologische Abteilung. Auch für diese beiden sind eigene Operationssäle, mit alien ir,odernen $\sum$ fülfsir,itteln großartig ausgestattet. - > Durch gedeckte Übergänge stehen m.it diesem Mittelbau westlich das Verwaltungsgebäude, östlich das DirektorWohnhaus in Verbindung. Das erstere umiaßt neben dem Hörsaal (80 Sitzplätze) Wohnungen für Ärzte, Hebammen und (80) Schülerinnen, die Poliklinik, das Sprechzimmer des Direktors.

Das Betriebsgebäud $\theta$ mit der Wäscherei und den Obduktionsräurnen und Laboratorium liegt völlig getrennt von dem anderen Gebäudekomplex auf dew. großen Hinterland -* jetzt Gartenund Gemüseland $-<$ ausgiebigem Raum für spätere Erweiterungsbedürfnisse.

Das Ganze macht in dem überaus gefälligen Aufbau, dem sinnvollen künstlerischen Schjx,uck einen erfreuenden, anheimelnden Eindruck, der mit den einfachsten Mitteln erreicht ist. Das empfindet man besonders an,ch in dem in der Mitte des Entbindungshauses gelegenen Taufsaal, der neben anderem auch den Wöchnerinnen als Tagrauro dient und dem Großberliner Hebammenverein für seine Sitzungen zur Verfügung gestellt ist. 
Die Anstalt bietet zunächst mit Ausnahme der FamilienWohnungen für Direktor, Betriebsinspektor, Masclónenpersonal Platz für 342Erwachsene und 150 Säuglinge, 210 Hausschwangeren, Wöchnerinnen und Kranken, SO Schülerinnen, Anstaltspersonal. Gesamtaufwand ca. 2 3/4 Millionen Mark.

Die Provinz Brandenburg hat ein großzügiges Vorbild für die Ausbildung ihrer Hebarr.n .en geschaffen, eine Anstalt, die sich ebenbürtig neben die neuesten und vollendetsten Frauenkliniken stellt. Wir wünschen lebhaft unserm Kollegen Hammerschlag, daß es ihm gelingt, diese Neuschöpfung, an deren Vollendung er einen so weitgehenden Anted hat, den ho hen Anforderungen entsprechend zii entwickeln, die er selbst in seiner Eröffnungsrede an die neuzeitliche Ausbildung des deutschen Hebammenstandes ge stellt hat! Er wird sich dadurch nicht nur um diesen Stand, auch $u \prod i \mathrm{~d} £ 1 / 8 \mathrm{~S}$ allgemeine Volkswohl hochverdient machen! A. Martin.

Näheres sowie die sehr sehönen Skizzen und Abbildungen enthält die Festschrift, welche im Auftrag des Landesdirektors der Provinz vom Archi-tektur-Verlag „Der Zirkel”, Berlin W 66, Wühelmstr. 48, veröffentlicht worden ist. 